\title{
Parental factors associated with screen time in pre-school children in primary-care practice: a TARGet Kids! study
}

\author{
Catherine S Birken ${ }^{1, *}$, Jonathon Maguire ${ }^{2}$, Magda Mekky ${ }^{1}$, Cedric Manlhiot ${ }^{3}$, \\ Carolyn E Beck ${ }^{1}$, Sheila Jacobson ${ }^{1}$, Michael Peer ${ }^{1}$, Carolyn Taylor $^{1}$, \\ Brian W McCrindle ${ }^{3}$ and Patricia C Parkin ${ }^{1}$ for the TARGet Kids! collaboration \\ 'Division of Paediatric Medicine, Department of Pediatrics, The Hospital for Sick Children, University of Toronto, \\ 555 University Avenue, Toronto, Ontario, Canada M5G 1X8: ${ }^{2}$ The Applied Health Research Centre, \\ St. Michael's Hospital, Li Ka Shing Knowledge Institute, University of Toronto, Toronto, Ontario, Canada: \\ ${ }^{3}$ Division of Cardiology, The Hospital for Sick Children, Heart Centre, University of Toronto, Toronto, \\ Ontario, Canada
}

Submitted 4 July 2010: Accepted 5 February 2011: First published online 5 April 2011

\begin{abstract}
Objective: To identify child and parental factors associated with screen time in 3-year-old children.

Design: Observational study.

Setting: Participants were recruited from a large primary-care paediatric group practice in Toronto, Canada.

Subjects: Healthy 3-year-old children were included. A questionnaire was completed by their parents on screen time. Descriptive statistics and linear regression models were used to assess associations between child screen time and selected factors. Multivariable models included factors from the univariate analysis with $P<0 \cdot 1$. Estimated effects and $95 \% \mathrm{CI}$ are reported.

Results: A total of 157 children were enrolled ( $91 \%$ recruitment). The mean screen time per weekday was $104 \mathrm{~min}$ (similar for weekend day). In all, 10\% of children had a television (TV) in their bedroom; 59\% consumed at least one meal while watching TV; and $81 \%$ of parents had household rules about screen time. Controlling for maternal education and age, eating lunch and dinner in front of the screen and mother being employed were associated with an increase in child weekday screen time of 96 (95\% CI 30, 192), 42 (95\% CI 12, 90) and 36 (95\% CI 6, 72) $\mathrm{min} / \mathrm{d}$, respectively. Eating lunch in front of the screen and an increase of $1 \mathrm{~h}$ of parental screen time were associated with an increase of 78 (95\% CI 36, 132) and $12(95 \%$ CI 6,18$) \mathrm{min} / \mathrm{d}$ in child weekend screen time. Family rules decreased child weekend screen time by 30 (95\% CI 6, 54) $\mathrm{min} / \mathrm{d}$.

Conclusions: Interventions that include these important parental factors should be evaluated for their effectiveness in reducing screen time.
\end{abstract}

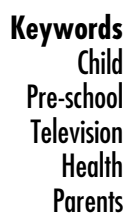

Children are spending an increasing amount of their time engaged in activities involving screen time, which is defined as time spent watching television (TV), DVD or video, or playing computer or video games. The Canadian Paediatric Society recommends that pre-school children watch $\leq 1 \mathrm{~h}$ of TV per day ${ }^{(1)}$ and the American Academy of Pediatrics recommends that children over the age of 2 years watch $\leq 2 \mathrm{~h}$ of TV per day ${ }^{(2)}$. TV viewing has been associated with important health outcomes, including delayed language development, aggressive behaviour, cigarette smoking in children ${ }^{(3-5)}$ and overweight and obesity ${ }^{(6-13)}$. Some studies have shown associations between screen time and BMI in this young age group ${ }^{(8,14,15)}$. For example, in very-low-income pre-school children, the presence of a TV in the bedroom was associated with increased BMI ${ }^{(8)}$.
There is compelling evidence that obesity prevention in the primary-care paediatrician's office should be focused on pre-school children ${ }^{(16-18)}$. Understanding factors associated with screen time in young children may provide opportunities to develop targeted interventions to reduce screen time and prevent overweight and obesity in young children. Studies to date have not focused on modifiable parental factors such as parental rules about screen time ${ }^{(19,20)}$. A recent systematic review of correlates of screen viewing in young children identified variables including demographic (e.g. parents' educational level) and sociocultural (e.g maternal depression) factors, as well as family structure (e.g single parent), and concluded that research is needed to test modifiable variables (including parental correlates) of screen time ${ }^{(21)}$. The objective of the present study was 
to identify child and parental factors associated with increased screen time in healthy 3-year-old children that may be targeted using interventions implemented in the primary-care practice setting to reduce screen time.

\section{Methods}

Children were recruited at their 3-year-old well-child visit to a large primary-care paediatric group practice in Toronto, Canada, which is part of TARGet Kids! (Toronto Applied Research Group), a paediatric primary-care research network of child health practitioners, researchers and policy makers. Exclusion criteria included nonEnglish-speaking parents who could not complete the questionnaire, and children with significant hearing or visual impairment or developmental delay that may affect screen time use and behaviours. After consent and enrolment, a research assistant reviewed a parent selfadministered questionnaire on screen time including: child and family demographics (parents' age, educational level, employment, mother's country of birth, child's age, attending daycare), screen ownership, location, common viewing times and parental screen-viewing factors (rules about screen time, parents' screen time duration, meals with the TV switched on). Items in the questionnaire were derived from the Canadian Community Health Survey ${ }^{(22)}$ and from other published research on screen time in children ${ }^{(6,7,9)}$. Outcome measures used were the sum of each reported child weekday and weekend day screen time. Screen time was defined as the time when the child was in a room with the TV or video or DVD switched on, when the child was using the computer and when the parent was using the computer for non-work-related activities, or playing video games. Data are presented as means with SD and frequencies with $95 \% \mathrm{CI}$ as appropriate.
Linear regression models (using maximum likelihood estimates) were used to test the univariate associations between screen time and selected potential associated factors. Selected variables were included in a multivariable model if the univariable $P$ value was $<0 \cdot 1$, using backward variable selection. All regression models were mathematically transformed using the Poisson distribution to account for the skewed distribution of screen time. Missing values were imputed using mean values. Estimated effect and 95\% CI were reported. All statistical analyses were performed using the SAS statistical software package version 9·1 (SAS Institute Inc., Cary, NC, USA). Ethical approval was obtained from the Research Ethics Board, Hospital for Sick Children, Toronto, Canada.

\section{Results}

A total of 157 children were enrolled in the present study, with a recruitment rate of $91 \%$ (sixteen did not consent; eleven did not meet the eligibility criteria). In all, $50 \%$ of children were female and $34 \%$ attended pre-school or daycare; $62 \%$ of mothers were born in Canada, $47 \%$ reported having completed a university degree and $81 \%$ were employed part time or full time. The families had a median of two TV sets, two DVD or video machines and one computer in their homes. A total of $10 \%$ of the children had a TV in their bedroom and $44 \%$ were able to view a TV from their main dining area; $59 \%$ of children ate at least one meal in a room with the TV switched on; $81 \%$ of parents reported having household rules about watching TV (Table 1). The mean reported weekday screen time was $104 \mathrm{~min}$, with $69 \mathrm{~min}$ watching TV, $28 \mathrm{~min}$ watching a DVD or video and 6 min on the computer. There was no significant difference in weekday and weekend day screen time (Table 1).

Table 1 Screen-time factors by weekday and weekend day: duration, viewing-time periods, meals with the TV switched on and parental factors

\begin{tabular}{|c|c|c|c|c|}
\hline \multirow[b]{2}{*}{ Screen-time factors } & \multicolumn{2}{|c|}{ Weekday } & \multicolumn{2}{|c|}{ Weekend day } \\
\hline & Mean or \% & $95 \% \mathrm{Cl}$ & Mean & $95 \% \mathrm{Cl}$ \\
\hline \multicolumn{5}{|l|}{ Duration of screen time $(\mathrm{min} / \mathrm{d})$} \\
\hline TV & 69 & 58,80 & 69 & 58,80 \\
\hline DVD or video & 28 & 21,35 & 35 & 27,43 \\
\hline Computer & 6 & 3,9 & 7 & 4,10 \\
\hline Video games & 1 & 0,2 & 2 & 0,4 \\
\hline \multicolumn{5}{|l|}{ Most common viewing-time periods (hours; \%) } \\
\hline 08.00-10.00 & 32 & 25,40 & 39 & 32,47 \\
\hline $16.00-18.00$ & 33 & 26,41 & 29 & 22,37 \\
\hline $18.00-20.00$ & 36 & 29,43 & 33 & 26,41 \\
\hline \multicolumn{5}{|l|}{ Meals eaten with the TV switched on (\%) } \\
\hline Breakfast & 31 & 24,38 & 30 & 24,38 \\
\hline Lunch & 11 & 7,17 & 13 & 8,19 \\
\hline Dinner & 17 & 12,24 & 12 & 7,18 \\
\hline Snack & 38 & 29,48 & 42 & 33,52 \\
\hline \multicolumn{5}{|l|}{ Parental factors (\%) } \\
\hline Have household rules about child viewing & 81 & 74,87 & N/A & - \\
\hline Watch TV with child (most or all the time) & 44 & 30,45 & N/A & - \\
\hline
\end{tabular}

TV, television; N/A, not applicable. 
Table 2 Univariable linear regression analysis: risk factors associated with screen time

\begin{tabular}{|c|c|c|c|c|}
\hline \multirow[b]{2}{*}{ Risk factor } & \multicolumn{2}{|c|}{ Weekday screen time (min) } & \multicolumn{2}{|c|}{ Weekend day screen time (min) } \\
\hline & Mean & $95 \% \mathrm{Cl}$ & Mean & $95 \% \mathrm{Cl}$ \\
\hline \multicolumn{5}{|l|}{ Screen ownership and location } \\
\hline Each additional TV in the home & $25^{\star}$ & 9,41 & $22^{*}$ & 8,36 \\
\hline TV present in child's bedroom & $96^{\star}$ & 44,147 & $99^{*}$ & 55,142 \\
\hline TV in view from dining area & 18 & $-14,51$ & $30^{*}$ & 3,58 \\
\hline \multicolumn{5}{|l|}{ Most common viewing-time period (hours) } \\
\hline $08.00-10.00$ & $49^{*}$ & 15,83 & 18 & $-10,47$ \\
\hline $16.00-18.00$ & 7 & $-28,43$ & -9 & $-40,23$ \\
\hline $18.00-20.00$ & $59^{\star}$ & 26,93 & 18 & $-11,48$ \\
\hline \multicolumn{5}{|l|}{ Meals eaten with the TV switched on } \\
\hline Breakfast & $52^{*}$ & 18,86 & $72^{*}$ & 45,100 \\
\hline Lunch & $69^{\star}$ & 18,120 & $122^{*}$ & 85,159 \\
\hline Dinner & $85^{\star}$ & 44,126 & $126^{\star}$ & 87,165 \\
\hline Snack & 33 & $-9,76$ & 12 & $-24,47$ \\
\hline \multicolumn{5}{|l|}{ Parental factors } \\
\hline Each added hour of parental weekday screen time & $49^{*}$ & 33,66 & $34^{\star}$ & 18,50 \\
\hline Have household rules about child viewing & $-48^{*}$ & $-8,-88$ & -21 & $-56,14$ \\
\hline Watch TV with child & 22 & 0,43 & 15 & $-5,35$ \\
\hline
\end{tabular}

TV, television.

${ }^{*} P<0.05$.

In univariable analyses (see Table 2), factors associated with increased child screen time included higher number of TV sets in the home, TV in the child's bedroom, TV viewing at mealtime, TV viewing in the morning and increased parental screen time. Family rules about screen time reduced screen time. For weekend days, the only additional factor that was associated with increased child screen time was a TV in view from the dining area. In multivariable analysis, controlling for maternal education and age, an increase in total minutes per day of child 'weekday' screen time was associated with eating lunch (96 (95\% CI 30, 192) $\mathrm{min} / \mathrm{d}$ ) and dinner in front of the screen (42 (95\% CI 12, 90) $\mathrm{min} / \mathrm{d}$ ) and with the mother being employed (36 (95\% CI 6, 72) $\mathrm{min} / \mathrm{d})$. An increase in total minutes per day of child 'weekend' screen time was associated with eating lunch in front of the screen (78 (95\% CI $36,132) \mathrm{min} / \mathrm{d})$ and an increase of $1 \mathrm{~h}$ of parental screen time $(12(95 \%$ CI 6,18$) \mathrm{min} / \mathrm{d})$. Family rules decreased child weekend screen time by 30 (95\% CI 6, 54) $\mathrm{min} / \mathrm{d}$.

\section{Discussion}

Our study showed that eating meals in front of the screen, mother's employment and parental screen time are associated with increased screen time, and that the existence of a parental rule about screen time is associated with decreased screen time, in pre-school children. An association between parental screen time rules and screen time has not been identified in this age group before. Strengths of the study include a thorough investigation of child and parental factors related to screen time in a healthy population of 3-year-old children. Limitations of the study include an absence of a validated measure of screen time. We used a developmentally appropriate measure of screen time exposure (being awake in a room with the TV switched on) ${ }^{(6)}$, compared with other studies that ask about time 'watching TV'. Postulated mechanisms associated with screen time and obesity (e.g exposure to food advertising ${ }^{(23)}$ ) occur during TV exposure, not only when children are engaged in 'watching TV'. Parental report of child screen time provides accurate estimates of TV-viewing times, compared with videotaped observation $(r=0 \cdot 70)$, and other methods (including diaries) were not used because of burden on families. The estimates of screen time use in our study were similar to those of other national and international studies ${ }^{(4,6,24)}$. Maternal mental health was not measured in the present study, and has been reported to affect child screen time ${ }^{(25)}$. Daycare type or direct data from daycare were not collected. The families in the present study had similar sociodemographics compared with the population of Toronto ${ }^{(26)}$.

Our study confirmed results from Dubois et al. ${ }^{(19)}$ showing an association between eating meals in front of the screen and total screen time, in an even younger population of 3-year-old children. Mechanisms to explain the associations between TV viewing during mealtime and increased BMI include alterations in satiety signals and effects of food advertising ${ }^{(23,27,28)}$. We also identified associations between parental and child screen time, as shown in a population of pre-school children in Greece ${ }^{(20)}$. Parents who are exposed to increased screen time themselves may not be as concerned about the amount of screen time that their children are exposed to. A qualitative study in parents of young children showed that parents were concerned with the content but not the amount of screen time ${ }^{(29)}$. Dennison et $a l^{(8)}$ showed that $40 \%$ of verylow-income pre-school children in New York State had a TV in their bedroom, and this was associated with increased BMI. A total of $10 \%$ of children in our study 
reported having a TV in their bedroom, and this factor was not significantly associated with total screen time, confirming results from the recent systematic review ${ }^{(21)}$. Differences in these results may be related to the different socio-economic status of the patient samples ${ }^{(4,6,8)}$.

Parental rules regarding mealtime TV viewing were found to mediate the relationship between maternal education and screen time in a large sample of pre-school children in Australia ${ }^{(30)}$. In our study, we found an association between total screen time and a general family rule related to screen time. Other parenting strategies, as they relate to screen time, have not been explored in the literature.

The present study identified several modifiable parental factors that may be tested in interventional trials in this population, including not consuming meals in front of the screen, modifying parental screen time and developing family rules regarding screen time. Longitudinal data investigating patterns of viewing over time and changes in parental factors would enhance understanding and may identify optimal timing for interventions. Developing and testing interventions that focus on parenting strategies as they relate to screen time may be important subsequent steps in this age group.

\section{Acknowledgements}

The present study was supported in part by a Paediatric Consultants Research Grant, Hospital for Sick Children, Toronto. This funding organization was not involved in any of the following: design and conduct of the study; collection, management, analysis and interpretation of data; and preparation, review or approval of the manuscript. The authors have no conflict of interest to declare. C.S.B. and P.C.P. were involved in study concept and design, in analysis and interpretation of data, as well as in obtaining funds for the study; C.S.B., P.C.P., M.M., S.J., M.P. and C.T. were involved in acquisition of data; C.S.B. drafted the manuscript; C.S.B., P.C.P., C.E.B., B.W.M. and J.M. were involved in critical revision of the manuscript for important intellectual content; C.S.B. and C.M. conducted statistical analysis; M.M. and P.C.P. provided administrative, technical and material support. The authors acknowledge contributions by research staff including Laura Burr, Stephanie Clairmont and Kate Smith.

\section{References}

1. Canadian Paediatric Society Psychosocial Paediatrics Committee (2003) Impact of media use on children and youth. Paediatr Child Health 8, 301-317.

2. Committee on Communications, American Academy of Pediatrics \& Strasburger VC (2006) Children, adolescents and advertising. Pediatrics 118, 2563-2569.

3. Christakis DA, Gilkerson J, Richards JA et al. (2009) Audible television and decreased adult words, infant vocalizations, and conversational turns: a population-based study. Arch Pediatr Adolesc Med 163, 554-558.
4. Wake M, Hesketh K \& Waters EE (2003) Television, computer use and body mass index in Australian primary school children. J Paediatr Child Health 39, 130-134.

5. Gidwani PP, Sobol A, DeJonh W et al. (2002) Television viewing and initiation of smoking among youth. Pediatrics 110, $505-508$.

6. Lumeng J, Rahnama S, Appugliese D et al. (2006) Television exposure and overweight risk in preschoolers. Arch Pediatr Adolesc Med 160, 417-422.

7. Christakis DA, Ebel BE, Rivara FP et al. (2004) Television, video, and computer games usage in children under 11 years of age. J Pediatr 145, 652-656.

8. Dennison BA, Erb TA \& Jenkins PL (2002) Television viewing and television in the bedroom associated with overweight risk among low-income preschool children. Pediatrics 109, 1028-1035.

9. Gortmaker SL, Must A, Sobol AM et al. (1996) Television viewing as a cause of increased obesity among children in the United States, 1986-1990. Arch Pediatr Adolesc Med 150, 356-362.

10. Dietz WH Jr \& Gortmaker SL (1985) Do we fatten our children at the television set? Obesity and television viewing in children and adolescents. Pediatrics 75, 807-812.

11. Hancox RJ, Milne BJ \& Poulton R (2004) Association between child and adolescent television viewing and adult health: a longitudinal birth cohort study. Lancet 364 , $257-262$.

12. Jago R, Baranowski T, Baranowski JC et al. (2005) BMI from 3-6 y of age is predicted by TV viewing and physical activity, not diet. Int J Obes (Lond) 29, 557-564.

13. Crespo CJ, Smit E, Troiano RP et al. (2001) Television watching, energy intake and obesity in US children: results from the third National Health and Nutrition Examination Survey, 1988-1994. Arch Pediatr Adolesc Med 155, 360-365.

14. Rey-Lopez JP, Vicente-Rodriguez G, Biosca M et al. (2008) Sedentary behavior and obesity development in children and adolescents. Nutr Metab Cardiovasc Dis 18, 242-251.

15. Marshall SJ, Biddle SJ, Gorely T et al. (2004) Relationships between media use, body fatness and physical activity in children and youth: a meta-analysis. Int J Obes Relat Metab Disord 28, 1238-1246.

16. Perrin EM, Finkle JP \& Benjamin JT (2007) Obesity prevention and the primary care pediatrician's office. Curr Opin Pediatr 19, 354-361.

17. Wardle J, Carnell S \& Cooke L (2005) Parental control over feeding and children's fruit and vegetable intake: how are they related? I Am Diet Assoc 105, 227-232.

18. Mikkila V, Rasanen L, Raitakari OT et al. (2005) Consistent dietary patterns identified from childhood to adulthood: the cardiovascular risk in Young Finns Study. Br J Nutr 93 , 923-931.

19. Dubois L, Farmer A, Girard M et al. (2008) Social factors and television use during meals and snacks is associated with higher BMI among preschool children. Public Health Nutr 11, 1267-1279.

20. Kourlaba G, Kondake K, Liarigkovinos T et al. (2009) Factors associated with television viewing time in toddlers and preschoolers in Greece: the GENESIS study. J Public Health 31, 222-230.

21. Hoyos Cillero I \& Jago R (2010) Systematic review of correlates of screen-viewing among young children. Prev Med 51, 3-10.

22. Statistics Canada (2005) Canadian Community Health Survey, Cycle 2.2. January 2004 to December 2004. http://www.statcan. gc.ca/cgi-bin/imdb/p2SV.pl?Function $=$ getSurvey\&SDDS $=5049$ \&lang $=\mathrm{en} \& \mathrm{db}=\mathrm{imdb} \& \mathrm{adm}=8 \& \mathrm{dis}=2$ (accessed September 2006).

23. Kotz K \& Story M (1994) Food advertisements during children's Saturday morning television programming: are 
they consistent with dietary recommendations? $J \mathrm{Am}$ Dietetic Assoc 94, 1296-1300.

24. Gable S, Chang Y \& Krull JL (2007) Television watching and frequency of family meals are predictive of overweight onset and persistence in a national sample of school aged children. J Am Diet Assoc 107, 53-61.

25. Burdette HL, Whitaker RC, Kahn RS et al. (2003) Association of maternal obesity and depressive symptoms with television-viewing time in low income preschool children. Arch Pediatr Adolesc Med 157, 894-899.

26. Statistics Canada (2007) Toronto, Ontario (Code535) (table). 2006 Community Profiles. 2006 Census. The Online Catalogue (92-591-XWE). http://www12.statcan.ca/census-recensement/
2006/dp-pd/prof/92-591/index.cfm?Lang $=\mathrm{E}$

(accessed December 2010)

27. Matheson DM, Killen JD, Wang Y et al. (2004) Children's food consumption during television viewing. Am J Clin Nutr 79, 1088-1094.

28. Bellissimo N, Pencharz PB, Thomas SG et al. (2007) Effect of television viewing at mealtime on food intake after a glucose preload in boys. Pediatr Res 61, 745-749.

29. He M, Irwin JD, Sangster Bouck LM et al. (2005) Screenviewing behaviors among preschoolers: parents' perceptions. Am J Prev Med 29, 120-125.

30. Hesketh K, Ball K, Crawford D et al. (2007) Mediators of the relationship between maternal education and children's TV viewing. Am J Prev Med 33, 41-47. 